\title{
Effects of aerobic training on heart rate
}

\author{
Marcos B. Almeida ${ }^{1}$ and Claudio Gil S. Araújo ${ }^{1,2}$
}

\begin{abstract}
Regular physical exercise is an important factor to reduce the indexes of cardiovascular and all causes morbimortality. However, there is, apparently, additional and independent benefits of the regular practice of physical exercise and the improvement of the level of aerobic condition. Heart rate (HR) is mediated primarily by the direct activity of the autonomic nervous system (ANS), specifically through the sympathetic and parasympathetic branches activities over the sinus node autorhythmicity, with predominance of the vagal activity (parasympathetic) at rest, that is progressively inhibited since the onset of the exercise. The HR behavior has been widely studied during different conditions and protocols associated to the exercise. A reduction of the cardiac vagal tone (parasympathetic function) and consequently a diminished HR variability in rest, independently of the protocol of measurement used, is related to an autonomic dysfunction, chronic-degenerative diseases and increased mortality risk. Individuals with high levels of aerobic condition have a lower resting HR, along with a larger parasympathetic activity or smaller sympathetic activity, but it is not necessarily a direct consequence of the exercise training, as long as other inherent adaptations to the aerobic conditioning can influence the resting HR. The HR response in the onset of the exercise represents the integrity of the vagus nerve, and the HR recovery on the post-exercise transient also denotes important prognostic information; by the way, individuals that have a slow HR recovery in the first minute post-exercise have increased mortality risk. In conclusion, the physio-
\end{abstract}

\footnotetext{
1. Programa de Pós-Graduação em Educação Física da Universidade Gama Filho - Rio de Janeiro, RJ.

2. Clinimex - Clínica de Medicina do Exercício - Rio de Janeiro, RJ.

Received in 27/11/02

Approved in 14/3/03
}

Correspondence to:

Dr. Claudio Gil S. Araújo

Clínica de Medicina do Exercício - Clinimex (www.clinimex.com.br)

Rua Siqueira Campos, 93/101

22031-070 - Rio de Janeiro, RJ

E-mail:cgaraujo@iis.com.br logical mechanisms modulating HR during or after an exercise program are not totally clear, and further studies are needed.

Key words: Training. Heart rate. Autonomic nervous system. Exercise.

\section{INTRODUCTION}

The regular practice of physical exercises is an important factor to reduce morbidity and mortality rates of cardiovascular and all other conditions ${ }^{1,2}$; there also seems to have further and independent benefits from the practice of physical exercises and improvement of the aerobic condition $^{3-6}$, which speaks for their being practiced more and more frequently. The American Heart Association recommends individuals to practice physical exercises in most days of the week, every day if possible, with intensity ranging from moderate to strenuous, according to their physical capability, for a period of 30 minutes or more ${ }^{7}$.

Even though moderate exercises enhance health conditions, there are recent and consistent evidences that high intensity or strenuous exercises have even more significant positive effects on lipid profile ${ }^{8}$, reducing up to two times mortality rates over a decade ${ }^{9-12}$.

Acute and chronic effects of physical exercises on the human body have been targeted by many researches over the last few decades ${ }^{13-18}$, and are identified as responses to exercise, such as higher HR at the initial transient of the exercise, and adjustments to training, with a lower HR for the same intensity of submaximal exercise, respectively.

Because it is easy to measure, heart rate (HR) behavior has been extensively studied under different exercise-related types and conditions. HR is primarily controlled by direct activity of the autonomic nervous system (ANS), through actions on its sympathetic and parasympathetic branches on the sinus node autorhytmicity, especially resting vagal activity (parasympathetic), which is progressively inhibited since the exercise was started ${ }^{19}$, and sympathetic when exercise intensity is further incremented (figure 1). Different mechanisms act to adjust HR at different moments of a physical exercise. For instance, the mechanism through which HR raises on the first four seconds of a physical exercise has been extensively studied, including under 


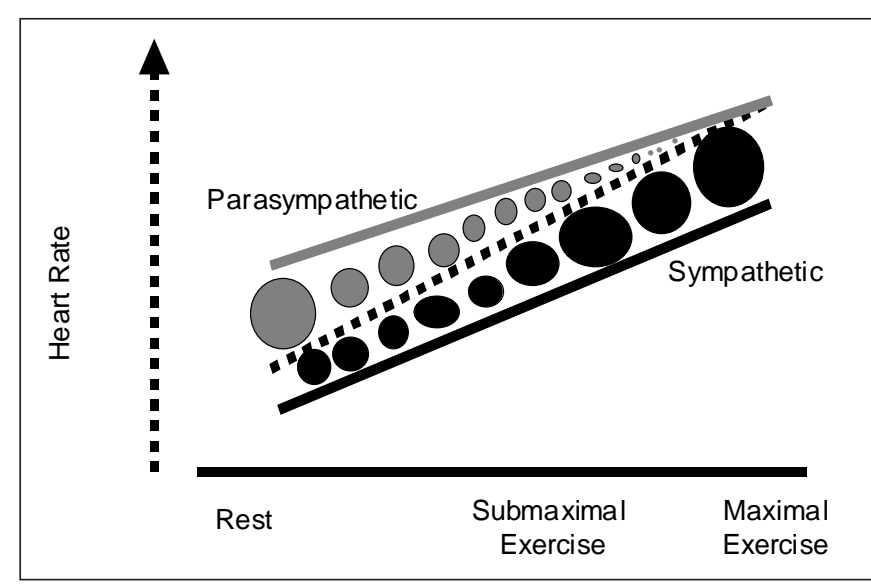

Fig. 1 - Heart rate autonomic control at rest and at exercise. Parasympathetic role decreases when intensity of exercise is increased, and the opposite happens with the sympathetic role.

the effect of pharmacological block ${ }^{20-22}$, and is almost exclusively mediated by vagal inhibition, with no significant sympathetic role ${ }^{20}$, partly from different times of latency from the two branches to this physiological stress.

HR variability was originally studied by Hon and Lee ${ }^{23}$ in newborns, and has been the target of many researches over the past few years. At a search with the key word "heart rate variability" on MedLine, there were over 6,000 references, 32\% between the years 1999 and 2002, showing a raising interest on the theme within the academic/scientific fields. HR variations or variability can be measured within the time and frequency domains, with specific protocols for each domain ${ }^{24-30}$, even with specificity enough for an isolated assessment of cardiac vagal tone (parasympathetic branch) in the transition from rest to dynamic exercise ${ }^{20}$.

A reduction of the cardiac vagal tone, thus of HR variability, regardless of the measuring protocol, is related to autonomic dysfunction, chronic-degenerative diseases, and increased mortality risk ${ }^{31-37}$, thus representing an important indicator of health status ${ }^{38,39}$. An isolated decrease of HR variability reflects a two- to five-fold increase in the relative mortality risk due to a cardiac event ${ }^{33,40}$; when associated to a significant decrease of baroreflex sensitivity $(<3 \mathrm{~ms} / \mathrm{mmHg})$, this relative risk may reach a 7 -fold increase $^{33}$. On the other hand, in individuals with congestive heart failure, even small increases in HR variability indices, such as standard-deviation of normal RR intervals (time domain), may decrease mortality risk in up to $20 \%{ }^{32}$. For this reason, and for its predominance on resting, cardiac vagal activity has been addressed in a number of trials, especially when it relates to physical activity.

Today, at the light of science, one cannot deny that aerobic training leads to improvement in the maximum oxygen uptake $^{15,41,42}$, due to, at least in part, an increase of cardiac output from an increase in the systolic volume. Maximal HR does not tend to change, whereas somewhat smaller values may be seen in rest and, especially, during submaximal exercise ${ }^{43}$, and are probably related to mechanisms such as increase of venous return and myocardial contractility ${ }^{44}$. Furthermore, maximum $\mathrm{O}_{2}$ uptake, both absolute, and gender and age-related, is an important longevity factor, i.e., the higher the aerobic conditions of an individual, the smaller his/her mortality risk ${ }^{3,45,46}$ (table 1 ). These adjustments of HR behavior from aerobic training may also be due to changes in the sympathetic-vagal balance or intrinsic adaptations, such as improvement in the atrioventricular conduction system ${ }^{47}$. Some studies suggest that the mere practice of physical exercises is not enough to effectively decrease mortality risk, being necessary that the training program be capable of promoting adjustments in both, the individual's aerobic condition $3,45,46$ and the autonomic function ${ }^{48}$.

It remains unclear if the improvement of the aerobic condition from training enhances cardiac vagal tone, thus resting-HR variability. Therefore, the purpose of this review is to discuss the effects of aerobic training on the autonomic nervous system to control resting HR, and in the initial and

TABLE 1

Mortality relative risk according to aerobic condition

\begin{tabular}{ccc}
\hline & $\begin{array}{c}\text { Aerobic } \\
\text { condition* }\end{array}$ & $\begin{array}{c}\text { RR } \\
\text { (Cl 95\%) }\end{array}$ \\
Laukkanen et al., 2001 & $>10.6$ & 1.0 (ref) \\
(asymptomatic individuals) & $9.3-10.6$ & $0.71-3.01$ \\
& $7.9-9.2$ & $1.44-5.39$ \\
& $<7.9$ & $2.02-7.32$ \\
\hline Kavanagh et al., 2002 & $<4.2$ & 1.0 (ref) \\
(individual with & $4.2-6.3$ & $0.54-0.71$ \\
cardiovascular disease) & $>6.3$ & $0.33-0.47$ \\
\hline Myers et al., 2002 & $1.0-5.9$ & $3.0-6.8$ \\
(asymptomatic individuals) & $6.0-7.9$ & $1.5-3.8$ \\
& $8.0-9.9$ & $1.1-2.8$ \\
& $10.0-12.9$ & $0.7-2.2$ \\
(individuals with & $>13.0$ & 1.0 (ref) \\
\hline cardiovascular conditions) & $1.0-4.9$ & $3.3-5.2$ \\
& $5.0-6.4$ & $2.4-3.7$ \\
& $6.5-8.2$ & $1.7-2.8$ \\
& $8.3-10.6$ & $1.4-2.2$ \\
& $>10.7$ & 1.0 (ref) \\
\hline
\end{tabular}

* Aerobic condition measured in METs.

RR: Relative risk for cardiovascular mortality. ref.: Value of reference. 
final exercise transients, i.e., the potential of aerobic training in inducing physiological changes of the cardiac vagal tone.

This review was based primarily on original studies in humans of different medical and physical conditions (levels of physical activity) ranging from individuals with severe heart conditions, even heart-transplanted subjects, to healthy, but sedentary individuals to high-performance athletes.

\section{EFFECTS ON RESTING-HR}

A low resting HR reflects a good health condition, whereas higher values are apparently related to a higher mortality risk ${ }^{49}$. A mistake often made in sports area is to use resting-HR as an indicator of the degree of aerobic conditioning, since the association between low resting-HR and maximal aerobic power is quite modest, and may be due to higher resting vagal activity ${ }^{50}$, reducing diastolic depolarization rate and prolonging duration of the cardiac cycle, primarily on account of a proportionally longer diastole ${ }^{13}$. However, can training induce higher resting vagal activity, and therefore be accountable for lower resting-HR?

Studies suggest that well-trained or physically well-fit (aerobically) individuals present a lower resting-HR, suggestive of higher parasympathetic activity ${ }^{51-55}$ or lower sympathetic activity ${ }^{56}$. However, except for the later, a crosssectional analysis does not allow us to conclude that training was responsible for such adjustment on the ANS. These studies did not take into consideration the level of aerobic conditioning and the autonomic function of athletes prior to training; by knowing that there is an important genetic influence in determining HR variability ${ }^{57}$, one could speculate that those individuals could have better cardiovascular adjustment upon training for having a better prior cardiac vagal tone ${ }^{58}$. Uusitalo et al. ${ }^{59}$ and Bonaduce et al. ${ }^{60}$, after longitudinal studies, noted a reduction of resting-HR, even though significant changes in autonomic indicators were not seen. Exercise-induced bradycardia can also be due to intrinsic adaptation of the sinus node ${ }^{61}$.

A lower resting-HR can also be consequence of other factors derived from a training program ${ }^{60}$, such as the increase of venous return and systolic volume. With the improvement of the venous return, there is an increase in the systolic volume, and according to Frank-Starling law, when there is an increase in the volume of blood in its cavities, there is an increase in heart contractility ${ }^{62}$. To keep restingheart output constant, there is a decrease of HR in response to a higher systolic volume, and these adaptations are expected in individuals with better aerobic conditioning ${ }^{62}$, regardless of their autonomic function. However, will training effects on cardiorespiratory variables also modify ANS?

\section{EFFECTS ON EXERCISE-HR}

As previously discussed, HR behavior during the exercise is mediated by ANS. HR variability is the oscillation in time between consecutive myocardial contractions (systoles $)^{23}$.

Studies with selective pharmacological block ${ }^{22}$ showed the exclusive role of the vagus nerve in HR response at the initial transient of the exercise ${ }^{20,21}$, with predominance of the vagal activity at rest that is gradually inhibited at submaximal exercise ${ }^{63}$ both active and passive ${ }^{64-66}$, up to the maximum level of exercise, when parasympathetic activity is apparently totally inhibited ${ }^{67}$, causing smaller or absence of HR variability.

In the initial seconds of the exercise, HR increases due to inhibition of vagal activity, which not only increases atria contractility, but also conduction velocity of the ventricle depolarization wave from AV node ${ }^{62}$, regardless of the level of intensity of the exercise ${ }^{68,69}$ and aerobic conditioning of healthy individuals ${ }^{70,71}$. On other hand, an individual who does not elevate significantly his/her HR in the beginning of the exercise, may be signalizing an impaired vagal activity $^{72}$. After this initial stage, as one goes on exercising, HR increases again, due to adrenergic overstimulation on sinus node, or due to increase of serum norepinephrine, or atrial mechanics distention and therefore, sinus node distention due to a higher venous return, and the increase in body's temperature and blood's acidity ${ }^{73}$.

While Tulppo et al. ${ }^{74}$ and Goldsmith et al. ${ }^{75}$ relate decrease of HR variability to age, in face of decreased physical fitness from aging, and that this could be reverted by maintaining or improving aerobic physical condition, results from Migliaro et al. ${ }^{76}$ and Byrne et al. ${ }^{77}$ suggest that age alone could be the main factor to decrease autonomic modulation, regardless of aerobic fitness.

The increase in maximal $\mathrm{O}_{2}$ uptake through aerobic training can lessen the age-related decrease of baroreflex sensitivity ${ }^{78,79}$. A program of mild-intensity exercises would be enough to show some improvement in the autonomic function of healthy adults ${ }^{80}$ or those with chronic heart failure $^{81}$, even without direct training supervision ${ }^{82}$; changes on vagal activity caused by physical training would be central, possibly directly on baroreflex, whereas the sympathetic activity would be primarily related to peripheral changes (vasoconstriction) ${ }^{82}$. These changes can be seen already in the first weeks of training in individuals with coronary heart disease ${ }^{83}$ and post-myocardial infarction $(\mathrm{MI})^{84,85}$. Even though Seals et al. ${ }^{86}$ have suggested that such improvements should be further evidenced in individuals with abnormal cardiac function, believing that aerobic training would have a smaller impact on HR variability of healthy individuals, Melanson and Freedson ${ }^{87}$, Stein et al. ${ }^{88}$, Al- 
Ani et al. ${ }^{89}$, and Gallo Jr et al. ${ }^{90}$ reached significant outcomes with training on autonomic markers of healthy individuals, and Levy et al. ${ }^{91}$ further suggest that these gains would not be age-dependent. In spite of the different methodologies used, and the fact that time of effective training had ranged from six weeks to 12 months, the results were consonant, showing an increase in vagal activity due to an exercise program, or even a decrease in resting sympathetic activity, which aid to hemodynamic improvements ${ }^{56,92}$.

Duru et al. ${ }^{93}$ were not successful in investigating positive effects of the regular physical exercises in the autonomic function of post-MI individuals when compared to sedentary matches, as, although resting-HR being lower after training, variability indices (in frequency domain) are not significantly altered. On the other hand, in the control group, there was a significant decrease of these indices, showing an advanced stage of autonomic imbalance in favor of a sympathetic preponderance in individuals with post-MI left ventricular dysfunction. These results can be interpreted in another way: the regular practice of physical exercises can, at least, maintain sympatho-vagal balance under parasympathetic predominance in post-MI individuals, whereas sedentarism tends to increase sympathetic influence, even at rest. Other studies also failed in finding differentiated adaptations of ANS to a program of exercises. Loimaala et al. ${ }^{94}$ did not find differences on variability indices of apparently healthy sedentary individuals with age ranging from 35 to 55 years, after 5 months of training, even at night, when sympathetic activity is quite decreased and there is less interference of other variables, with improvement on resting-HR only, probably due to intrinsic adaptations.

On the other hand, another interesting aspect is that Boutcher and Stein ${ }^{58}$ have observed that individuals with better cardiac vagal tone respond better to an aerobic training, with higher gains in maximum oxygen uptake, and further decreasing resting-HR. Confirming the last studies, Uusitalo et al..$^{59}$ e Bonaduce et al. ${ }^{60}$, after investigating effects of high aerobic performance training on autonomic modulations of young athletes, did not find differences, neither for males nor females. It is possible that some changes in ANS activity, due to training, are observed only as a response to a stimulus, such as changes in posture or during exercise, but not in rest ${ }^{85,90}$, as in most protocols. One cannot state that failure in finding differences in autonomic functions due to training is due to measuring in rest, without taking into account the possibility of a ceiling-effect of ANS activities, which could justify the mere maintaining of the magnitude of sympathetic and parasympathetic influences on HR variability after training period in athletes or physically very well-fit individuals.

\section{EFFECTS ON HR POST-EXERCISE RECOVERY}

Another very important aspect addressed by the literature over the last few years is post-exercise, maximal ${ }^{95-97}$ and submaximal ${ }^{98-100} \mathrm{HR}$ recovery. HR behavior at the final transient of the exercise is another indicator of vagus nerve integrity. HR fall at the end of the exercise does not replace other measurements of cardiac autonomic activity, but it is a remarkable complement to a medical and/or physical assessment of an individual ${ }^{101}$.

At the end of the exercise, special attention should be paid to HR behavior, as its lowering less than 12 beats per minute (bpm) if return to rest is active ${ }^{97}$ or $18 \mathrm{bpm}$ if passive, in the supine position ${ }^{102}$, at the first recovery minute after a maximum-exercise test, represents an unfavorable prognosis for relative-risk of cardiovascular mortality in asymptomatic individuals and cardiopaths $s^{95,97,102}$, i.e., for both initial and final transient, the smaller the HR variation, the higher the relative risk.

This stage of the exercise has been intensively investigated over the last few years, but results still differ as to the necessary time for total restore to post-exercise ANS resting levels. The time for HR to fall to resting levels depends on the interaction among autonomic functions, the level of physical fitness ${ }^{103,104}$, and also on the intensity of the exercise ${ }^{68,105}$. Recovery can take one hour after light or moderate exercise ${ }^{105}$, four hours after long-duration aerobic exercise ${ }^{106}$, and even up to 24 hours after intense or maximal exercise ${ }^{107}$. The mechanisms responsible for such discrepancies as to the time needed for total HR post-exercise recovery are not fully clear, and the following explanations are currently considered as the most plausible: decreased vagal activity ${ }^{105,108-110}$, sympathetic overactivity ${ }^{107,111}$ or even increase in the activity of both ANS branches, recovering balance with slight vagal predominance ${ }^{25}$. Five minutes after a moderate to intense exercise session, serum norepinephrine is still higher than when in rest ${ }^{110}$, suggesting higher sympathetic activity at this stage. However, one must take into account a latency time of about 2.5 minutes for serum norepinephrine to reach its peak ${ }^{112}$, leading us to wonder that the five-minute recovery time of this study could be too short. It seems that with aging, the time to norepinephrine be removed from the blood is slower, and cardiac rhythm remains faster for a longer time after the exercise. The decrease of post-exercise norepinephrine concentration comes along HR decrease, but there is indication that at the beginning of recovery, vagal modulation is primarily responsible for HR fall ${ }^{69,110}$.

Heart-transplanted individuals have a significantly slower HR recovery at the first minute post-exercise when compared to apparently healthy individuals ${ }^{113}$, endorsing the 
idea from Perini et al. ${ }^{110}$. Physical training can increase the delta between HR at the end of the exercise and at the beginning of recovery, and eight weeks of training would be enough to augment this difference within the first $30 \mathrm{sec}-$ onds post-exercise ${ }^{114}$, with no differences in outcome for gender or age group ${ }^{115}$; however, such adaptation may be lost in few weeks without training ${ }^{79,114}$. In children, recovery may be faster than in young adults due to their higher central cholinergic modulation ${ }^{116}$; there are differences for elders as well, in whom decrease of post-exercise serum norepinephrine takes longer ${ }^{117}$. Apparently, the time for total restoration of ANS activities is inversely related to the maximum level of $\mathrm{O}_{2}$ uptake ${ }^{55,106}$, in spite of Arai et al. ${ }^{63}$ not having found evidences in their results that indicated differences in variables such as: gender ${ }^{63,118}$, position of subject on recovery (seated or supine), and level of physical activity among healthy individual ${ }^{63}$. When healthy individuals were compared to heart-failure or heart-transplanted individuals, the former required shorter time for post-maximal exercise HR recovery; notwithstanding, HR variability measured under frequency domain at the peak of the exercise did not show differences among the groups, probably a sign of complete inhibition of vagal activity at this stage ${ }^{67}$. The groups of heart-failure and heart-transplanted individuals had reduced their HR less than $10 \mathrm{bpm}$ at the beginning of the recovery stage, which is compatible to a probable autonomic dysfunction and related to a high mortality risk $^{95-97}$.

\section{CONCLUSIONS}

As discussed in this review, HR variability has been studied at a number of trials over the last few years, especially its relation to a higher risk of cardiovascular mortality, a common finding in many of these trials. Vagal nerve activity (parasympathetic branch) is considered to be a cardiovascular protection factor; therefore, ANS dysfunction, particularly reduction of the cardiac vagal tone, translates in a significant increase of cardiovascular mortality risk. It is not clear if the regular practice of physical exercise can significantly increase ANS function, as shown by some evidences. Perhaps some of the changes that take place in HR control at rest and at exercise submaximal levels are consequence of intrinsic adaptations of the sinus node, or derived from other physiological changes, such as the increase of venous return and systolic volume, and improved myocardial contractility; or peripheral, such as improved oxygen extraction (oxygen arteriovenous difference) or enhanced $\mathrm{O}_{2}$ use to generate more work (mechanical efficiency), causing HR to reduce to those (submaximal) required levels.
Apparently, aerobically well-fit individuals present a more effective autonomic activity than sedentary ones, and there is indication that individuals with better cardiac vagal tone have a better response to aerobic training, which lead us to question whether aerobically well-fit athletes have a higher cardiac vagal tone due to training or those individuals with genetically higher cardiac vagal tone have a higher potential to become elite athletes if properly trained.

Certainly, the large variety of HR measuring methods, and the features and peculiarities of the samples and the outlines used in each trial, have added to differences among the results and their interpretations as to the effects of exercise and training on parasympathetic ANS and HR control.

In spite of the need of other studies on immediate and late acute effects, and chronic effects of physical exercise on the autonomic nervous system, especially of the parasympathetic component, identifying possible changes on the cardiac vagal tone, some conclusions could be reached.

\section{REFERENCES}

1. Blair SN, Kohl $3^{\text {rd }}$ HW, Barlow CE, Paffenbarger RS, Gibbons LW, Macera CA. Changes in physical fitness and all-cause mortality. A prospective study of healthy and unhealthy men. JAMA 1995;273:1093-8.

2. Centers for Disease Control. Coronary heart disease attributable to sedentary life-style - selected states, 1988. JAMA 1990;264:1390-2.

3. Myers J, Prakash M, Froelicher V, Do D, Partington S, Atwood JE. Exercise capacity and mortality among men referred for exercise testing. $\mathrm{N}$ Engl J Med 2002;346:793-801.

4. Willians PT. Physical fitness and activity as separate heart disease risk factors: a meta-analysis. Med Sci Sports Exerc 2001;5:754-61.

5. Erikssen G, Liestol K, Bjornholt J, Thaulow E, Sandvik L, Erikssen J. Changes in physical fitness and changes in mortality. Lancet 1998;352: 759-62.

6. McGinnis JM, Foege WH. Actual causes of death in the United States. JAMA 1993;270:2207-12.

7. Pearson TA, Blair SN, Daniels SR, Eckel RH, Fair JM, Fortmann SP, et al. AHA guidelines for primary prevention of cardiovascular disease and stroke: 2002 update. Consensus panel guide to comprehensive risk reduction for adult patients without coronary or other atherosclerotic vascular diseases. Circulation 2002;106:388-91.

8. Kraus WE, Houmard JA, Duscha BD, Knetzger KJ, Wharton MB, McCartney JS, et al. Effects of the amount and intensity of exercise on plasma lipoproteins. N Engl J Med 2002;347:1483-92.

9. Paffenbarger RS, Lee IM. Physical activity and fitness for health and longevity. Res Q Exerc Sport 1996;67:11-28.

10. Manson JE, Hu FB, Rich-Edwards JW, Colditz GA, Stampfer MJ, Willett WC, et al. A prospective study of walking as compared with vigorous exercise in the prevention of coronary heart disease in women. $\mathrm{N}$ Engl J Med 1999;341:650-8.

11. Manson JE, Greenland P, LaCroix AZ, Stefanick ML, Mouton CP, Oberman A, et al. Walking compared with vigorous exercise for the prevention of cardiovascular events in women. N Engl J Med 2002;347:71625 . 
12. Tanasescu M, Leitzmann MF, Rimm EB, Willet WC, Stampfer MJ, Hu FB. Exercise type and intensity in relation to coronary disease in men. JAMA 2002;288:1994-2000.

13. Nottin S, Vinet A, Stecken F, N'Guyen LD, Ounissi F, Lecoq AM, Obert P. Central and peripheral cardiovascular adaptations to exercise in endurance-trained children. Acta Physiol Scand 2002;175:85-92.

14. McGuirre DK, Levine BD, Williamson JW, Snell PG, Blomqvist CG, Saltin B, et al. A 30-year follow-up of the Dallas Bed Rest and Training Study. The effect of age on the cardiovascular response to exercise. Circulation 2001;104:1350-7.

15. McGuirre DK, Levine BD, Williamson JW, Snell PG, Blomqvist CG, Saltin B, et al. A 30-year follow-up of the Dallas Bed Rest and Training Study. The effect of age on the cardiovascular adaptation to exercise. Circulation 2001;104:1358-66.

16. Stratton JR, Levy WC, Cerqueira MD, Schwartz RS, Abrass IB. Cardiovascular responses to exercise. Effects of aging and exercise training in healthy men. Circulation 1994;89:1648-55.

17. Nóbrega ACL, Williamson JW, Araújo CGS, Friedman DB. Heart rate and blood pressure responses at the onset of dynamic exercise: effect of Valsalva manoeuvre. Eur J Appl Physiol 1994;68:336-40.

18. Ekblom B, Astrand PO, Saltin B, Stenberg J, Wallstrom B. Effect of training on circulatory response to exercise. J Appl Physiol 1968;24: $518-28$.

19. Ekblom B, Hermansen L. Cardiac output in athletes. J Appl Physiol 1968; 25:619-25

20. Araújo CGS, Nóbrega ACL, Castro CLB. Heart rate responses to deep breathing and 4-seconds of exercise before and after pharmacological blockade with atropine and propranolol. Clin Auton Res 1992;2:35-40.

21. Maciel BC, Gallo L Jr, Marin Neto JA, Lima Filho EC, Martins LE. Autonomic nervous control of the heart rate during dynamic exercise in normal man. Clin Sci (Colch) 1986;71:457-60.

22. Jose AD. Effect of combined sympathetic and parasympathetic blockade on heart rate and function in man. Am J Cardiol 1966;18:476-8.

23. Hon EH, Lee ST. Electronic evaluations of the fetal heart rate patterns preceding fetal death: further observations. Am J Obstet Gynecol 1965; 87:814-826.

24. Moraes RS, Ferlin EL, Polanczyk CA, Rohde LE, Zaslavski L, Gross JL, Ribeiro JP. Three-dimensional return map: a new tool for quantification of heart rate variability. Auton Neurosci 2000;83:90-9.

25. Oida E, Moritani T, Yamori Y. Tone-entropy analysis on cardiac recovery after dynamic exercise. J Appl Physiol 1997;82:1794-801.

26. European Society of Cardiology. Heart rate variability: Standards of measurement, physiological interpretation, and clinical use. Task Force of the European Society of Cardiology and the North American Society of Pacing Electrophysiology. Circulation 1996;93:1043-65.

27. Marfella R, Guigliano D, di Maro G, Acampora R, Giunta R, D’Onofrio F. The squatting test. A useful tool to assess both parasympathetic and sympathetic involvement of the cardiovascular autonomic neuropathy in diabetes. Diabetes 1994;43:607-12.

28. Castro CLB, Nóbrega ACL, Araújo CGS. Testes autonômicos cardiovasculares. Uma revisão crítica. Parte I. Arq Bras Cardiol 1992;59:7585.

29. Castro CLB, Nóbrega ACL, Araújo CGS. Testes autonômicos cardiovasculares. Uma revisão crítica. Parte II. Arq Bras Cardiol 1992;59:1518.

30. Wieling W, Borst C, Karemaker JM, Dunning AJ. Testing for autonomic neuropathy: initial heart rate response to active and passive changes of posture. Clin Physiol 1985;5: S5-23-7.

31. Tapanainen J, Thomsen P, Kober L, Torp-Pedersen C, Makikallio T, Still A, et al. Fractal analysis of heart rate variability and mortality after an acute myocardial infarction. Am J Cardiol 2002;90:347.
32. Bilchick KC, Fetics B, Djoukeng R, Fisher SG, Fletcher RD, Singh SN, et al. Prognostic value of heart rate variability in chronic congestive heart failure (Veterans Affairs' Survival Trial of Antiarrhythmic Therapy in Congestive Heart Failure). Am J Cardiol 2002;90:24-8.

33. La Rovere MT, Pinna GD, Hohnloser SH, Marcus FI, Mortara A, Nohara $\mathrm{R}$, et al. Baroreflex sensitivity and heart rate variability in the identification of patients at risk for life-threatening arrhythmias. Implications for clinical trials. Circulation 2001;103:2072-7.

34. Colhoun HM, Francis DP, Rubens MB, Underwood SR, Fuller JH. The association of heart rate variability with cardiovascular risk factors and coronary artery calcification. A study in type 1 diabetic patients and the general population. Diabetes Care 2001;24:1108-14.

35. Ribeiro AL, Moraes RS, Ribeiro JP, Ferlin EL, Torres RM, Oliveira E, Rocha MO. Parasympathetic dysautonomia precedes left ventricular systolic dysfunction in Chagas disease. Am Heart J 2001;141:260-5.

36. Nolan J, Batin PD, Andrews R, Lindsay SJ, Brooksby P, Mullen M, et al. Prospective study of heart rate variability and mortality in chronic heart failure. Results of the United Kingdom Heart Failure Evaluation Assessment of Risk Trial (UK-Heart). Circulation 1998;98:1510-6.

37. Singh JP, Larson MG, Tsuji H, Evans JC, O’Donnell CJ, Levy D. Reduced heart rate variability and new-onset hypertension. Insights into pathogenesis of hypertension: The Framingham Heart Study. Hypertension 1998;32:293-7.

38. Kikuya M, Hozawa A, Ohokubo T, Tsuji I, Michimata M, Matsubara M, et al. Prognostic significance of blood pressure and heart rate variabilities. The Ohasama Study. Hypertension 2000;36:901-6.

39. Moser M, Lehofer M, Sedminek A, Lux M, Zapotoczky HG, Kenner T, et al. Heart rate variability as a prognostic tool in cardiology. A contribution to the problem from a theoretical point of view. Circulation 1994; 90:1078-82.

40. La Rovere MT, Bigger Jr JT, Marcus FI, Mortara A, Schwartz PJ, for the ATRAMI (Autonomic Tone and Reflexes After Myocardial Infarction) investigators. Baroreflex sensitivity and heart rate variability in prediction of total cardiac mortality after myocardial infarction. Lancet 1998; 351:478-84.

41. Seal DR, Chase PB. Influence of physical training on heart rate variability and baroreflex circulatory control. J Appl Physiol 1989;66:1886-95.

42. Blomqvist CG, Saltin B. Cardiovascular adaptations to physical training. Ann Rev Physiol 1983;45:169-89.

43. Fox EL, Bartels RL, Billings CE, O’Brien R, Bason R, Mathews DK. Frequency and duration of interval programs and changes in aerobic power. J Appl Physiol 1975;38:481-4.

44. Yoshiga CC, Higuchi M. Heart rate is lower during ergometer rowing than during treadmill running. Eur J Appl Physiol 2002;87:97-100.

45. Kavanagh T, Mertens DJ, Hamm LF, Beyene J, Kennedy J, Corey P, et al. Prediction of long-term prognosis in 12169 men referred for cardiac rehabilitation. Circulation 2002;106:666-71.

46. Laukkanen JA, Lakka TA, Rauramaa R, Kuhanen R, Venäläinen JM, Salonen R, et al. Cardiovascular fitness as a predictor of mortality in men. Arch Intern Med 2001;161:825-31.

47. Stein R, Moraes RS, Cavalcanti AV, Ferlin EL, Zimerman LI, Ribeiro JP. Atrial automaticity and atrioventricular conduction in athletes: contribution of autonomic regulation. Eur J Appl Physiol 2000;82:155-7.

48. La Rovere MT, Bersano C, Gnemmi M, Specchia G, Schwartz PJ. Exercise-induced increase in baroreflex sensitivity predicts improved prognosis after myocardial infarction. Circulation 2002;106:945-9.

49. Greenland P, Daviglus ML, Dyer AR, Liu K, Huang CF, Goldberger JJ, et al. Resting heart rate is a risk factor for cardiovascular and noncardiovascular mortality: the Chicago Heart Association Detection Project in Industry. Am J Epidemiol 1999;149:853-62. 
50. Jensen-Urstad K, Saltin B, Ericson M, Storck N, Jensen-Urstad M. Pronounced resting bradycardia in male elite runners is associated with high heart variability. Scand J Med Sci Sports 1997;7:274-8.

51. Aubert AE, Beckers F, Ramaekers D. Short-term heart rate variability in young athletes. J Cardiol 2001;37: S85-8.

52. Spalding TW, Jeffers LS, Porges SW, Hatfield BD. Vagal and cardiac reactivity to psychological stressors in trained and untrained men. Med Sci Sports Exerc 2000;32:581-91.

53. Shin K, Minamitani H, Onishi S, Yamazaki H, Lee M. Autonomic differences between athletes and nonathletes: spectral analysis approach. Med Sci Sports Exerc 1997;29:1482-90.

54. Shin K, Minamitani H, Onishi S, Yamazaki H, Lee M. The power spectral analysis of heart rate variability in athletes during dynamic exercise - part I. Clin Cardiol 1995; 18:583-6.

55. Dixon E, Kamath MV, McCartney N, Fallen E. Neural regulation of the heart rate in endurance athletes and sedentary controls. Cardiovasc Res 1992;26:713-9.

56. Chacon-Mikahil MPT, Forti VAM, Catai AM, Szrajer JS, Golfetti R, Martins LEB, et al. Cardiorespiratory adaptations induced by aerobic training in middle-age men: the importance of a decrease in sympathetic stimulation for the contribution of dynamic exercise tachycardia. Brazilian J Med Biol Res 1998;31:705-12.

57. Singh JP, Larson MG, O'Donnell CJ, Tsuji H, Evans JC, Levy D. Heritability of the heart rate variability. The Framingham Heart Study. Circulation 1999;99:2251-4.

58. Boutcher SH, Stein P. Association between heart rate variability and training response in sedentary middle-aged men. Eur J Appl Physiol 1995; 70:75-80.

59. Uusitalo ALT, Uusitalo AJ, Ruscko HK. Exhaustive endurance training for 6-9 weeks did not change in intrinsic heart rate and cardiac autonomic modulation in female athletes. Int J Sports Med 1998;19:532-40.

60. Bonaduce D, Petretta M, Cavallaro V, Apicella C, Ianniciello A, Romano $\mathrm{M}$, et al. Intensive training and cardiac autonomic control in high level athletes. Med Sci Sports Exerc 1998;30:691-6.

61. Catai AM, Chacon-Mikahil MP, Martinelli FS, Forti VAM, Silva E, Golfetti R, et al. Effects of aerobic exercise training on heart rate variability during wakefulness and sleep and cardiorespiratory responses of young and middle-age healthy men. Brazilian J Med Biol Res 2002;35: 741-52.

62. Clausen JP. Effect of physical training on cardiovascular adjustments to exercise in man. Physiol Rev 1977;57:779-815.

63. Arai Y, Saul JP, Albrecht P, Hartley LH, Lilly LS, Cohen RJ, Colucci WS. Modulation of cardiac autonomic activity during and immediately after exercise. Am J Physiol 1989;256:H132-41.

64. Nurhayati Y, Boutcher SH. Cardiovascular response to passive cycle exercise. Med Sci Sports Exerc 1998;30:234-8.

65. Nóbrega ACL, Williamson JW, Friedman DB, Araújo CGS, Mitchell $\mathrm{JH}$. Cardiovascular responses to active and passive cycling movements. Med Sci Sports Exerc 1994;26:709-14.

66. Nóbrega ACL, Araújo CGS. Heart rate transient at the onset of active and passive dynamic exercise. Med Sci Sports Exerc 1993;25:37-41.

67. Alonso DO, Forjaz CLM, Rezende LO, Braga AMFW, Barretto ACP, Negrão CE, et al. Comportamento da freqüência cardíaca e da sua variabilidade durante as diferentes fases do exercício físico progressivo. Arq Bras Cardiol 1998;71:787-92.

68. Baum K, Ebfeld D, Leyk D, Stegemann J. Blood pressure and heart rate during rest-exercise and exercise-rest transitions. Eur J Appl Physiol 1992; 64:134-8.

69. Araújo CGS. Fast "on" and "off" heart rate transients at different bicycle exercise levels. Int J Sports Med 1985;6:68-73.
70. Araújo CGS, Nóbrega ACL, Castro CLB. Vagal activity: effect of age, sex and physical pattern. Brazilian J Med Biol Res 1989;22:909-11.

71. Borst C, Wieling W, van Brederode JFM, Hond A, de Rijk LG, Dunning AJ. Mechanisms of initial heart rate response to postural change. Am J Physiol 1982;243:H676-81.

72. Nóbrega ACL, Castro CLB, Araújo CGS. Relative roles of the sympathetic and parasympathetic systems in the 4-s exercise test. Brazilian J Med Biol Res 1990;23:1259-62.

73. Araújo CGS. Fisiologia do exercício. In: Araújo WB, editor. Ergometria e cardiologia desportiva. Rio de Janeiro: Medsi, 1986;1-57.

74. Tulppo MP, Mäkikallio TH, Seppänen T, Laukkanen RT, Huikuri HV. Vagal modulation of heart rate during exercise: effects of age and physical fitness. Am J Physiol 1998;274:H424-9.

75. Goldsmith RL, Bigger JT, Bloofield DM, Steinman RC. Physical fitness as a determinant of vagal modulation. Med Sci Sports Exerc 1997;29: 812-7.

76. Migliaro ER, Contreras P, Bech S, Etxagibel A, Castro M, Ricca R, et al. Relative influence of age, resting heart rate and sedentary life style in short-term analysis of heart rate variability. Brazilian J Med Biol Res 2001;34:493-500.

77. Byrne EA, Fleg JL, Vaitkevicius PV, Wright J, Porges SW. Role of aerobic capacity and body mass index in the age-associated decline in heart rate variability. J Appl Physiol 1996;81:743-50.

78. Hunt BE, Farquhar WB, Taylor JA. Does reduced vascular stiffening fully explain preserved cardiovagal baroreflex function in older, physically active men? Circulation 2001;103:2424-7.

79. Frederiks J, Swenne CA, Bruschke AVG, van der Velde ET, Maan AC, Tenvoorde BJ, et al. Correlated neurocardiologic and fitness changes in athletes interrupting training. Med Sci Sports Exerc 2000;32:571-5.

80. Uusitalo ALT, Laitinen T, Väisänen SB, Länsimies E, Rauramaa R. Effects of endurance training on heart rate and blood pressure variability. Cli Physiol \& Func Im 2002;22:173-9.

81. Malfatto G, Branzi G, Riva B, Sala L, Leonetti G, Facchini M. Recovery of cardiac autonomic responsiveness with low-intensity physical training in patients with chronic heart failure. Eur J Heart Fail 2002;4:15966.

82. Radaelli A, Coats AJ, Leuzzi S, Piepoli M, Meyer TE, Calciati A, et al. Physical training enhances sympathetic and parasympathetic control of heart rate and peripheral vessels in chronic heart failure. Clin Sci (Colch) 1996;91: S92-4.

83. Iellamo F, Legramante JM, Massaro M, Raimondi G, Galante A. Effects of a residential exercise training on baroreflex sensitivity and heart rate variability in patients with coronary artery disease. A randomized, controlled study. Circulation 2000;102:2588-92.

84. Oya M, Itoh H, Kato K, Tanabe K, Murayama M. Effects of exercise training on the recovery of the autonomic nervous system and exercise capacity after acute myocardial infarction. Jpn Circ J 1999;63:843-8.

85. La Rovere MT, Mortara A, Sandrone G, Lombardi F. Autonomic nervous system adaptations to short-term exercise training. Chest 1992;101: 299S-303.

86. Seals DR, Hurley BF, Hagberg JM, Schultz J, Linder BJ, Natter L, et al. Effects of training on systolic time intervals at rest and during isometric exercise in men and women 61 to 64 years old. Am J Cardiol 1985;55: 797-800.

87. Melanson EL, Freedson OS. The effect of endurance training on resting heart rate variability in sedentary adult males. Eur J Appl Physiol 2001; 85:442-9.

88. Stein PK, Ehsani AA, Domitrovich PP, Kleiger RE, Rottman JN. Effect of exercise training on heart rate variability in healthy older adults. Am Heart J 1999;138:567-76. 
89. Al-Ani M, Munir SM, White M, Towend J, Coote JH. Changes in R-R variability before and after endurance training measured by power spectral analysis and by the effect of isometric muscle contraction. Eur $\mathbf{J}$ Appl Physiol 1996;74:397-403.

90. Gallo Jr L, Maciel BC, Marin-Neto JA, Martins LEB. Sympathetic and parasympathetic changes in heart rate control during dynamic exercise induced by endurance training in man. Brazilian J Med Biol Res 1989; 22:631-43.

91. Levy WC, Cerquera MD, Harp GD, Johannessen KA, Abrass IB, Schwartz RS, et al. Effect of endurance exercise training on heart rate variability at rest in healthy young and older men. Am J Cardiol 1998; 82:1236-41.

92. O'Sullivan SE, Bell C. Training reduces autonomic cardiovascular responses to both exercise-dependent and -independent stimuli in humans. Auton Neurosci 2001;91:76-84.

93. Duru F, Candinas R, Dziekan G, Goebbels U, Myers J, Dubach P. Effect of exercise training on heart rate variability in patients with newonset left ventricular dysfunction after myocardial infarction. Am Heart J 2000; 140:157-61.

94. Loimaala A, Huikuri H, Oja P, Pasanen M, Vuori I. Controled 5-mo aerobic training improves heart rate but not heart rate variability or baroreflex sensitivity. J Appl Physiol 2000;89:1825-9.

95. Nishime OE, Cole CR, Blackstone EH, Pashkow FJ, Lauer MS. Heart rate recovery and treadmill exercise score as predictors of mortality in patients referred for exercise ECG. JAMA 2000;284:1392-8.

96. Pierpont GL, Stolpman DR, Gornick CC. Heart rate recovery as an index of parasympathetic activity. J Auton Nerv Syst 2000;80:169-74.

97. Cole CR, Blackstone EH, Pashkow FJ, Snader CE, Lauer MS. Heart rate recovery immediately after exercise as a predictor of mortality. $\mathrm{N}$ Engl J Med 1999;341:1351-7.

98. Morshedi-Meibodi A, Larson MG, Levy D, O’Donnel CJ, Vasan R. Heart rate recovery after treadmill exercise testing and risk of cardiovascular disease events (The Framingham Heart Study). Am J Cardiol 2002;90: 848-52.

99. Cole CR, Foody JM, Blackstone EH, Lauer MS. Heart rate recovery after submaximal exercise testing as a predictor of mortality in a cardiovascularly healthy cohort. Ann Intern Med 2000;132:552-5.

100. Lauer MS, Francis GS, Okin PM, Pashkow FJ, Snader CE, Marwick TH. Impaired chronotropic response to exercise stress testing as a predictor of mortality. JAMA 1999;281:524-9.

101. Shetler K, Marcus R, Froelicher VF, Vora S, Kalisetti D, Prakash M, et al. Heart rate recovery: validation and methodologic issues. J Am Coll Cardiol 2001;38:1980-7.

102. Watanabe J, Thamilarasan M, Blackstone EH, Thomas JD, Lauer MS Heart rate recovery immediately after treadmill exercise and left ventricular systolic dysfunction as predictors of mortality. The case of stress echocardiography. Circulation 2001;104:1991-6.

103. Hatfield BD, Spalding TW, Santa Maria DL, Porges SW, Potts JT, Byrne EA, et al. Respiratory sinus arrhythmia during exercise in aerobically trained and untrained men. Med Sci Sports Exerc 1998;30:206-14.
104. Darr KC, Bassett DR, Morgan BJ, Thomas DP. Effects of age and training status on heart rate recovery after peak exercise. Am J Physiol 1988; 254:H340-3.

105. Terziotti P, Schena F, Gulli G, Cevese A. Post-exercise recovery of autonomic cardiovascular control: a study by spectrum and cross-spectrum analysis in humans. Eur J Appl Physiol 2001;84:187-94.

106. Hautala A, Tulppo MP, Mäkikallio TH, Laukkanen R, Nissilä S, Huikuri HV. Changes in cardiac autonomic regulation after prolonged maximal exercise. Clin Physiol 2001;21:238-45.

107. Furlan R, Piazza S, Dell'Orto S, Gentile E, Cerutti S, Pagani M, Malliani A. Early and late effects of exercise and athletic training on neural mechanisms controlling heart rate. Cardiovasc Res 1993;27:482-8.

108. Melanson EL. Resting heart rate variability in men varying in habitual physical activity. Med Sci Sports Exerc 2000;32:1894-901.

109. Imai K, Sato H, Hori M, Kusuoka H, Ozaki H, Yokoyama H, et al. Vagally mediated heart rate recovery after exercise is accelerated in athletes but blunted in patients with chronic heart failure. J Am Coll Cardiol 1994;24:1529-35.

110. Perini R, Orizio C, Comandè A, Castellano M, Beschi M, Veicsteinas A. Plasma norepinephrine and heart rate dynamics during recovery from submaximal exercise in men. Eur J Appl Physiol 1989;58:879-83.

111. Dilaveris PE, Zervopoulos GA, Michaelides AP, Sideris SK, Psomadaki ZD, Gialafos EJ, et al. Ischemia-induced reflex sympathoexcitation during the recovery period after maximal treadmill exercise testing. Clin Cardiol 1998;21:585-90.

112. Watson RDS, Hamilton CA, Jones DH, Reid JL, Stallard TJ, Littler WA. Sequential changes in plasma noradrenaline during bicycle exercise. Clin Sci 1980;58:37-43.

113. Desai MY, Peña-Almaguer E, Mannting F. Abnormal heart rate recovery after exercise as a reflection of abnormal chronotropic response. Am J Cardiol 2001;87:1164-9.

114. Sugawara J, Murakami H, Maeda S, Kuno S, Matsuda M. Change in post-exercise vagal reactivation with exercise training and detraining in young men. Eur J Appl Physiol 2001;85:259-63.

115. Hao SC, Chai A, Kligfield P. Heart rate recovery response to symptomlimited treadmill exercise after cardiac rehabilitation in patients with coronary artery disease with and without recent events. Am J Cardiol 2002;90:763-5.

116. Ohuchi H, Suzuki, Yasuda K, Arakaki Y, Echigo S, Kamiya T. Heart rate recovery after exercise and cardiac autonomic nervous activity in children. Pediatr Res 2000;47:329-35.

117. Tasaki H, Serita T, Irita A, Hano O, Iliev I, Ueyama C, et al. A 15-year longitudinal follow-up study of heart rate and heart rate variability in healthy elderly persons. J Gerontol 2000;55A:M744-9.

118. Carter III R, Watenpaugh DE, Smith ML. Genome and hormones: gender differences in physiology selected contribution: gender differences in cardiovascular regulation during recovery from exercise. J Appl Physiol 2001;91:1902-7. 